\title{
Embedding report writing workshops into an undergraduate Environmental Science module through a subject specialist and learning developer partnership
}

\section{Robert Blake}

Lancaster University, Lancaster, UK

\section{Jacqueline Pates}

Lancaster University, Lancaster, UK

\begin{abstract}
In recent years, there has been an increasing need for all university students to receive help with learning to write. Consequently, there has been a shift away from a pure study skills approach towards embedding the teaching of writing into the mainstream curriculum. Embedded writing courses can be designed and delivered by various combinations of learning developer and subject specialist. Students view delivery by subject lecturers as more valuable, but subject specialist delivery may be challenging for those lecturers who feel it is outside their zone of expertise and consider writing as the province of learning developers. However, it is difficult for learning developers to contextualise such teaching in terms of subject values and expectations, and the shared knowledge of coursework assignments. By working through the different stages of teaching partnership, from cooperation to team teaching, both learning developer and subject specialist become empowered, facilitating the transition from teaching writing as a study skill to a fully embedded model.
\end{abstract}

Keywords: study skills; scientific writing; academic literacies; teaching partnerships, embedding.

\section{Introduction}

It has been recognised for some time that many students across disciplines enter higher education poorly equipped with writing skills (Winch and Wells, 1995; Wingate, 2006). This 
general trend is accentuated in the sciences as students often gravitate towards more numerical subjects when they are uncomfortable with written communication. Although the sciences do not require extensive essay writing to the same degree as the arts and social sciences, assessment for science students still centres on the written word. Thus, developing students' writing skills cannot be ignored in science subjects.

In UK universities, writing is frequently taught through study skills sessions, separate to the subject that the student is learning (Wingate, 2006). Although the evidence indicates that most university students would benefit from improving their writing, the integrated teaching of writing within modules is seen as an optional extra. However, recent research framed in an academic literacies context suggests that acquisition of subject-knowledge and writing have a complex relationship (Lea, 2004). Spiller and Fraser (1999: 36) state that 'learning to write articulately and with understanding about a subject cannot be separated from the acquisition of knowledge about the subject itself'. In addition, universities are starting to recognise that giving extensive support to individual students can become costly when the majority need some level of help. Therefore, there has been a recent move towards embedding the teaching of writing into the curriculum.

Partnerships between learning developers and subject specialists have a particular role in the teaching of writing in science and technology subjects. Academic scientists may feel that they are poorly equipped to deal with teaching writing. Informal discussions with colleagues indicate that their own writing skills are instinctive, and they often lack the language to explain why a piece of writing is correct or incorrect. Learning developers have an overview of writing across disciplines, and can bring different perspectives and examples of good practice. However, they lack detailed knowledge of the conventions and requirements of the individual disciplines they support.

This paper describes a three-year partnership of a subject specialist (SS) and a learning developer (LD) to redesign a report-writing course in Environmental Science (ES) and deliver it through team teaching. We explore the usefulness of genre analysis to produce report writing materials. In discussing team teaching, we highlight the value of discussion between co-teachers to make explicit tacit knowledge of report writing and argue that delivery by the SS is a goal of such partnerships. 


\section{Models and the process of embedding writing}

In this section, we look at two different approaches to teaching writing and the implications for a science curriculum. We then examine models of embedding and the roles of LD/SS partnerships to integrate writing into a module. Prior to the current phase of embedding the teaching of writing in mainstream courses, study skills courses were the most common form of provision. Generally, these courses have been offered centrally within a university by Learning Development or English for Academic Purposes (EAP) Units. The study skills approach views 'literacy as a set of atomised skills, which students have to learn and which are then transferable to other contexts' (Lea and Street, 1998). Thus, student writing can be viewed in the light of a deficit model in which problems can be 'fixed'. This is a remedial approach in which '... learning and teaching do not thrive if they are divorced from the students' overall teaching and learning experience' (Cottrell, 2001). In this model, scientific writing would be taught through generic workshops on report structure. However, this provision is limited in its abilities to address the varied requirements of the different scientific or technological disciplines (for example, reports in Computing differ to those in Environmental Science or Physics). Furthermore, within a subject, there may be a number of report sub-genres that undergraduates are required to learn. For example, in Environmental Science these might be laboratory reports, consultancy-style reports (aimed at a more general audience) or paper-style reports (aimed at a specialist audience).

A second limitation of the study skills model is that it is difficult for students to transfer knowledge of generic report structure to the specific requirements of a coursework assessment. As Lea and Street point out, 'this approach focuses on the surface features of language form and presumes that students can transfer their knowledge of writing unproblematically from one context to another' (Lea and Street, 2006).

For the SS and LD in the current study, the third key issue with a study skills approach is its lack of contextualisation in terms of subject values, assessment and writing practices in relation to the sub-genres of reports. In contrast, the academic literacies model focuses on how knowledge is constituted within a particular field (Lea and Street, 2006). It avoids a deficit view of writing as a cognitive skill learnt on an individual basis, concentrating instead on facilitating a shift in writing practices for all students. An example of this shift is the transition from the first to the second year of the Environmental Science degree discussed here. The academic literacies approach works well with embedding though LD 
and SS partnerships, as these can deal more effectively with epistemological issues than study skills sessions provided solely by LDs.

Next, we will look at different LD and SS partnerships and how these partnerships relate to embedding. In their model describing how EAP lecturers work with subject departments to support international students, Dudley-Evans and St John (1998) postulate three levels of cooperation and partnership (Table1). The first stage is cooperation with the SS, which involves the collection of information about the discipline such as key text types and typical texts, language, expectations and priorities. This information is used for teaching separate bolt-on sessions outside the curriculum delivered by the LD. This stage is classified as a study skills approach, as writing may be taught using generic skills-based techniques, with little attention paid to disciplinary sub-genres and knowledge. Writing tasks may be assigned separately from the work students are engaged with at that time. This separation can result in students not taking the tasks seriously or viewing them as not worthwhile.

Collaboration, Dudley-Evans and St Johns' second stage, involves close consultation about specific tasks, concepts and language. This is followed by supplementary classes, which are delivered by the LD either prior to the main lecture, to prepare for areas of difficulty, or afterwards to pick up problematic areas and language. Although such collaboration is one step away from embedding, it allows for the possibility of team teaching. This style has often been used to address the needs of specific groups, such as international and widening participation students, perceived as requiring remedial support. Dudley-Evans and St Johns' final stage is team teaching by the SS and LD, which can play a particularly useful part in embedding writing through their combined perspectives and experience. They point out that their relationship is vital and can break down if, for example, the LD fails to understand the subject content. The role of the SS here is to draw on his/her disciplinary knowledge in the teaching of writing and to contextualise the teaching of a sub-genre by reference to specific assignments. The SS can relate to the students as a fellow insider within the discipline.

Team teaching within a core module can facilitate embedding by addressing a complete cohort, rather than targeting specific groups such as international students. By working with the whole class, several advantages can be identified: (i) students with previously unrecognised support needs can be identified; (ii) the assessed work of all students can be improved, encouraging good students to aspire to higher grades; and (iii) specific student 
groups, such as international students, can continue to receive specialist support, but are also more closely integrated with their peers.

Table 1. Stages in subject specialist and learning developer partnerships in embedding writing (adapted from Dudley-Evans and St John, 1998).

\begin{tabular}{|c|c|c|}
\hline $\begin{array}{l}\text { WHO } \\
\text { LEADS }\end{array}$ & STAGE OF DEVELOPMENT & APPROACH TO WRITING \\
\hline \multirow[t]{4}{*}{$\begin{array}{l}\text { Learning } \\
\text { Developer }\end{array}$} & $\begin{array}{l}\text { Cooperation: learning developer } \\
\text { (+ subject specialist) } \\
\text { LD runs separate workshops using } \\
\text { information about study practices in } \\
\text { discipline from SS. May be generic or } \\
\text { geared for particular courses using } \\
\text { information supplied. }\end{array}$ & $\begin{array}{l}\text { Study skills } \\
\text { Teaching generic skills or writing workshops } \\
\text { but taught by LD only. Bolt-on approach. } \\
\text { Likely to deal broadly with genres rather than } \\
\text { specific sub-genres within courses. Teaching } \\
\text { of writing excludes disciplinary knowledge. }\end{array}$ \\
\hline & $\begin{array}{l}\text { Collaboration: subject specialist } \\
+ \text { learning developer } \\
\text { LD works with SS to prepare } \\
\text { preparatory class run before main } \\
\text { lecture or adjunct class to solve } \\
\text { problem areas post-lecture. }\end{array}$ & $\begin{array}{l}\text { Study skills } \\
\text { May be targeted at groups requiring remedial } \\
\text { provision e.g. courses with large numbers of } \\
\text { international or widening participation } \\
\text { students. } \\
\text { Limited use of disciplinary knowledge, but } \\
\text { subject conventions more to the fore. }\end{array}$ \\
\hline & $\begin{array}{l}\text { Team teaching: learning } \\
\text { developer + subject specialist } \\
\text { May initially be LD led, with SS as a } \\
\text { guest, then moving to equal roles; } \\
\text { finally SS led with LD assuming a } \\
\text { secondary role. }\end{array}$ & $\begin{array}{l}\text { Academic literacies: embedding } \\
\text { Discipline specific writing practices are } \\
\text { embedded within modules. Begins process of } \\
\text { integrating writing and subject knowledge. } \\
\text { May cover specific course assignments. } \\
\text { Aimed at the writing development of all } \\
\text { students in the programme, rather than } \\
\text { remedial provision targeted at specific } \\
\text { groups. }\end{array}$ \\
\hline & $\begin{array}{l}\text { Handover and consultancy: } \\
\text { subject specialist (+ learning } \\
\text { developer). } \\
\text { LD acts as a consultant or plays a } \\
\text { guest role. }\end{array}$ & $\begin{array}{l}\text { Academic literacies: embedded } \\
\text { Learning about writing and science closely } \\
\text { integrated. }\end{array}$ \\
\hline
\end{tabular}

Dudley-Evans and St Johns' model provides a useful starting point for examining how a LD and SS can work together. While useful in the context of EAP, HE has changed significantly since the 70s and 80s; student numbers have increased dramatically, less emphasis is placed on extended writing in schools and more international students are recruited. In response, there is growing momentum to embed the teaching of writing and other skills in the curriculum and extend this to all students. Therefore, we have attempted to modify Dudley-Evans and St Johns' model to take account of embedding writing in 
mainstream courses. In doing so, we have added a fourth stage of handover and consultancy.

There are a number of options for the design and delivery of embedded courses:

- They can be designed and taught by LDs in consultation with the target department;

- They can be developed and taught jointly by LD and SS;

- They can be run by SSs, with optional consultation from learning or professional development staff.

Looking at the first option, we have seen 'embedded' courses based on cooperation with lecturers that are part of mainstream courses, despite being delivered by LDs. The lack of specialist input, other than secondary input from the SS, and, hence, the degree of contextualisation that the SS as co-lecturer can provide about assessment, data analysis and presentation and above all subject content, means that these sessions are not truly integrated with the curriculum and therefore closer to a study skills approach.

The second team teaching partnership option to embed writing may often require the longterm commitment of both LD and SS. Their roles vary according to the SS's experience in teaching writing. These partnerships can be LD initiated and led with SS as the specialist informant adding specific information about subject content and assessment. This format is more likely with an early-career SS or in technological disciplines where teaching writing has not been considered part of the curriculum. Team teaching sessions can be jointly delivered with the SS dealing with content and assessment, and the LD focusing on writing and discourse. Alternatively, the SS can lead, with additional input from the LD. This is more likely to occur at a final stage of the partnership shortly before handover or where LD has been invited as guest, for example to teach part of the session dealing with a particular skill.

The third embedding option may involve an SS initiative or it may constitute our fourth stage of handover and consultancy. We see handover as the goal of the process when the teaching of writing is fully embedded. Here as much emphasis is placed on learning about the discipline as about the writing. Students are not just learning the mechanics of report structure, but also need to develop their understanding of the subject they are writing about in order to prioritise and select information and to develop coherent arguments. 
Wingate (1996) views such long-term embedded approaches as very successful yet problematic to put into practice. We believe that a scaffolded approach, in which the LD and SS work through the stages of partnership, is a valuable model for introducing the teaching of writing into scientific and technological disciplines.

\section{The evolution of a teaching partnership}

\section{Context}

Environmental Science at Lancaster lies between the 'traditional' sciences and the social sciences. Subject-specific material focuses on understanding the physical, chemical, geological and mathematical underpinning of environmental process, but communication and writing skills are recognised as being essential for the students' future careers as scientists. However, ES students have a wide-range of educational backgrounds, and many have chosen to study a science subject at university because they do not like writing. The need for students to write well is communicated to them both explicitly (through marking criteria) and implicitly (through feedback). For example, marginal notes may indicate where there are issues with poor grammar, style or structure, and these points may be reinforced in summary notes referenced to the marking criteria.

Within ES, writing skills are first taught in $1^{\text {st }}$ year, when most students take ENV121 Communicating Science, delivered by SS staff. However, across $1^{\text {st }}$ year, the majority of the assessment is based on highly structured work, often requiring only a few connected paragraphs. In contrast, in Part $2\left(2^{\text {nd }}\right.$ and $3^{\text {rd }}$ years $)$, students are required to write a range of reports for a variety of audiences. Further, students should critically evaluate sources and pull together multiple strands of evidence to form a coherent whole.

Immediately prior to the start of the $2^{\text {nd }}$ year, all students (approximately 70-80 annually) take part in a field course (ENV200 Carrock Fell), during which they study the impact of a disused mine on water quality. The assessment for the field course is a single piece of coursework, in the form of a report, due in at the end of the term. This course is followed by ENV201 Project Skills, a 10-week core module that aims to develop skills in data presentation and analysis and report writing, using the field course data and the associated report as a framework. The writing component, which is jointly delivered by the authors, focuses on helping students recognise the different requirements of Part 2 and to 
make that transition successfully. Here we discuss the evolution of our roles through the stages of a teaching partnership.

\section{The existing module}

ENV201 is a long-standing module; the previous lecturer initiated the introduction of writing skills and collaboration with the Student Learning Development Centre (SLDC), pioneering the embedding of skills into a science curriculum. When Jackie took over the module in 2006, writing was covered over a three-week period, during which time report structures, style and abstracts were covered. The SS and LD each took responsibility for a session, ensuring that students gained the benefit of their different perspectives, and both contributed to development of materials and session delivery.

The writing sessions were run with small groups (15 - 20 students). Although this small group size was amenable to highly interactive teaching, opportunities were limited by the amount of material covered; teaching was more by 'telling' than 'doing'. Students had one opportunity to practise the writing skills they were learning and receive feedback prior to submitting their final reports, by writing a fictitious abstract. The abstracts were reviewed in class and given individual feedback. This model was successful, but suffered from a lack of reinforcement.

The session devoted to report structure was limited to looking at the overall structure of a report. No time was available to work on the individual sub-sections or specialist scientific writing skills, such as presenting data. Limited time was available to analyse examples, and only two sample abstracts were discussed with students. Finally, the writing sessions were early in the term, but many students did not start writing their reports in earnest until some weeks later, leading to a disconnection between what they were learning and putting these skills into practice. Given the weaknesses identified above, the SS decided to rewrite the curriculum, building on the strengths in the existing model. More time would be devoted to writing skills, increasing opportunities for student activity and extending the collaboration between the SS and LD. 


\section{The new curriculum}

The new curriculum took as its starting point the piece of writing the students were working on that term, i.e. the Carrock Fell field report. The report was then broken down into its component parts (e.g. introduction, results, conclusions, etc) and each was worked on in turn (Table 2). We aimed to work on the topics in a sequence natural for the construction of a report (e.g. the session on abstracts was towards the end of term, when the reports were nearly complete). Each week we introduced the topic with a question and answer session, and outlined an approach to writing that section of the report based on genre analysis (see below). The class then worked through 'good' and 'bad' examples from the subject literature, analysing them according to the framework we had provided. The students then had a week in which to produce the relevant section of their own report. We concluded with a feedback session in which the class analysed selected examples from the cohort's work.

\section{Table 2. Outline of the topics covered.}

\begin{tabular}{ll}
\hline Week & Topic \\
\hline 1 & Report writing: standard lab reports \\
2 & Report writing: alternative styles \\
3 & Writing an introduction: structure and purpose \\
4 & Introduction to the Library and literature searching \\
5 & Using information sources: referencing, note taking and avoiding plagiarism \\
6 & Writing the results: using figures, tables and appendices effectively \\
7 & Writing the conclusions: tying the report together \\
8 & Writing an abstract: structure and function \\
\hline
\end{tabular}

Although on the surface, the focus of these sessions is learning to write, the emphasis throughout is on the report they are preparing for the field course. There is an ongoing discussion about the underlying science, during which the students are learning how to prioritise evidence, bring disparate strands together into a cohesive whole, organise data and frame research questions. As Wingate (2006) states 'It is ... necessary to teach students that knowledge is constantly developing, and that they are expected to question existing knowledge and contribute to its development... '. 


\section{Changing roles}

In this case study, the staff are both experienced teachers. The LD (Robert) had been involved in delivering the module, as described above, for several years. He also provides individual support to students across the Faculty of Science and Technology, works with several SSs teaching scientific writing on undergraduate and postgraduate modules, and runs student writing support groups. The SS (Jackie) is also an experienced lecturer, but despite a strong interest had not previously taught writing skills. Over four years our roles changed as follows:

Year 1: The module was taught following the old curriculum using team teaching. The SS initiated course redesign to address the weaknesses identified above.

Year 2: The SS redesigned the course; she selected topics to cover the full 10 weeks of the module, linking the programme with coursework objectives. However, she was unsure about how to deliver the material and consulted with the LD. The LD has a bank of Scientific Writing teaching materials and experience of tailoring materials to departmental needs with SS input. The LD suggested using an approach based on genre analysis (see below). The LD and SS delivered the sessions jointly, but the LD was the overall leader.

Year 3: Formal student feedback, centred around an end of module questionnaire comprising a standard question set and free text responses, was used to make adjustments to the teaching. Of the free text responses, half referred to the writing component of the module. The general methodology was praised, but issues were identified with the order in which the topics were encountered and the amount of work required. Consequently, the content and ordering of the topics was refined and the coursework demands adjusted. Overall, the module was much better received in Year 2 than in Year 1 (overall module score of 4.09/5.00, up from 2.91/5.00).

In addition, the LD stepped back from the delivery. In general, the LD briefly introduced the generic issues found in the week's topic, leading into a discussion of subject specific examples. The SS led the remainder of the session, with input from the LD. Session leadership had shifted from the LD to the SS, who had also taken on the 'writing voice'. An important part of a successful transition from LD to SS leadership is the LD stepping back at an appropriate time. The LD needs to be able to recognise when the SS has gained enough knowledge and confidence to deliver the material effectively. 
Year 4: The LD is now playing a purely consultative role. The SS has taken ownership of the teaching materials and their delivery. The LD is still involved in the background, helping to develop new materials where needed and coming in to co-teach in guest slots. We felt that the continued presence of the LD in the classroom was desirable, as it starts to break down barriers students sometimes experience about seeking individual help from learning support staff.

Table 3 summarises the knowledge and experience that the LD and SS bring to the teaching partnership. Both play important roles in teaching writing; although the SS may have limited experience of teaching writing and is unlikely to have the language or materials available to do so easily, s/he provides an essential context in which to place writing development. The LD will not be involved in assessing student work, and therefore does not have a complete insight into subject conventions and priorities. In addition, students tend to take more account of the person marking their work, often believing that there is some hidden knowledge that only the SS has. Finally, the LD has limited knowledge of the subject and therefore it is difficult to contextualise examples. Therefore, leadership by the SS is the ideal situation, as and when they have the skills and confidence to deliver the materials.

Table 3. Comparison of the knowledge and experience that the LD and SS bring to the teaching partnership.

\begin{tabular}{l|l}
\hline Subject Specialist & Learning Developer \\
\hline Knowledge of assessment across degree & Experience of working with staff and \\
programme: current coursework & producing customised workshops in \\
assignments in $2^{\text {nd }}$ year, relationships with & courses. \\
past (foundation work in $1^{\text {st }}$ year) and future & \\
assessments (dissertation in $3^{\text {rd }}$ year). & \\
\hline Broad knowledge of subject specific content & Experience of teaching scientific writing and \\
across degree. & modelling writing workshops. \\
\hline
\end{tabular}




\begin{tabular}{l|l}
\hline $\begin{array}{l}\text { More detailed knowledge of individual } \\
\text { students' backgrounds, both academic and } \\
\text { personal. }\end{array}$ & $\begin{array}{l}\text { Experience of one-to-one working with } \\
\text { Science and Technology students, in } \\
\text { relation to their knowledge / difficulties / } \\
\text { issues / feedback. }\end{array}$ \\
\hline $\begin{array}{l}\text { Own knowledge and experience of writing } \\
\text { papers in discipline. }\end{array}$ & $\begin{array}{l}\text { Overview of writing requirements in different } \\
\text { disciplines across faculty. }\end{array}$ \\
\hline
\end{tabular}

\section{Development of materials based on genre analysis}

Based on experience in teaching report writing to international students, the LD suggested using materials developed from genre analysis. Swales (1990) defines a genre as 'a class of communicative events' for a group who share a common communicative goal. It shares four characteristics: structure, style, contents and intended audience (Swales, 1990). In the analysis of a genre, texts are analysed as a series of steps or 'moves'. This approach works particularly well for science and technology texts such as reports and papers, as they often have a standard, prescribed format. Our key text was Weissburg and Buker's (1990) 'Writing Up Research: Experimental Research Report Writing for Students of English', which provides an analysis of experimental scientific report structure section by section and the moves within sections. It also provides very useful guidance on language features such as tense usage in different sections and modality in making claims about data. The LD has long used this book as a tool for analysing report, paper and dissertation structure.

Our teaching process is illustrated here with reference to writing introductions. We used Weissburg and Buker's analysis as a starting point for the weekly sessions, and then examined journal articles selected by the SS to see how closely they conformed to the model, before producing our revised model (Table 4). The next step was to identify papers with well-organised introductions and to provide a contrasting paper with a poorly organised series of moves. Using our model, we asked the students to work in groups to identify the moves in the examples provided and evaluate the success of each in terms of clarity and readability. Encouraging students to critique published examples by 'experts' was valuable in developing their confidence as writers. 
Table 4. Key stages in writing introductions to reports (adapted slightly from Weissburg and Buker, 1990).

\begin{tabular}{|l|l|}
\hline 1 & $\begin{array}{l}\text { General statements about the field of research to provide the reader with a setting for } \\
\text { the problem to be reported. }\end{array}$ \\
\hline 2 & $\begin{array}{l}\text { More specific statements about the aspects of the problem already studied by other } \\
\text { researchers i.e. indicate current knowledge of problem. }\end{array}$ \\
\hline 3 & $\begin{array}{l}\text { Statements that indicate the need for more investigation i.e. highlighting a gap in } \\
\text { research data or methodology. This provides the context for } 4 \text { : your purpose and } \\
\text { hypotheses. }\end{array}$ \\
\hline 4 & $\begin{array}{l}\text { Very specific statements giving the purpose/objectives/hypotheses or research } \\
\text { questions of your study. It also begins the introduction to your work. }\end{array}$ \\
\hline 5 & Explanation of the value or justification for carrying out the study. \\
\hline 6 & Signposting of structure of report or dissertation (optional: longer reports only). \\
\hline
\end{tabular}

\section{Task-based approach}

In the redesign of the course, a key criterion for the SS was to change the way in which we taught the module. Therefore, we replaced previous lecture-style approach of telling students about report structure, interspersed with some questions, with a task-based approach borrowed from second language teaching (e.g. Willis, 1996). As discussed above, students analysed examples from the literature using genre analysis. However, while excerpts from papers are a useful tool to illustrate structure, they may seem removed from the students' actual writing. Therefore, each week the students were given a short writing task, based on the report they were working towards (e.g. write a detailed outline of your introduction based on the moves discussed today). The tasks were not summatively assessed and were submitted electronically to facilitate fast turnaround.

During the feedback class, the SS used a tablet laptop with the whole lecture group to conduct live editing by peer feedback of selected examples (Figure 1). Any of the student's work could be selected for feedback and the SS identified both positive and negative examples to illustrate particular points. At the end of the class, students were asked to identify the things they needed to do to improve their work and the key feedback points were consolidated with a set of written notes. We also used Post-it notes to collect 
students' questions during the class and responded via our virtual learning environment (VLE) discussion forum.

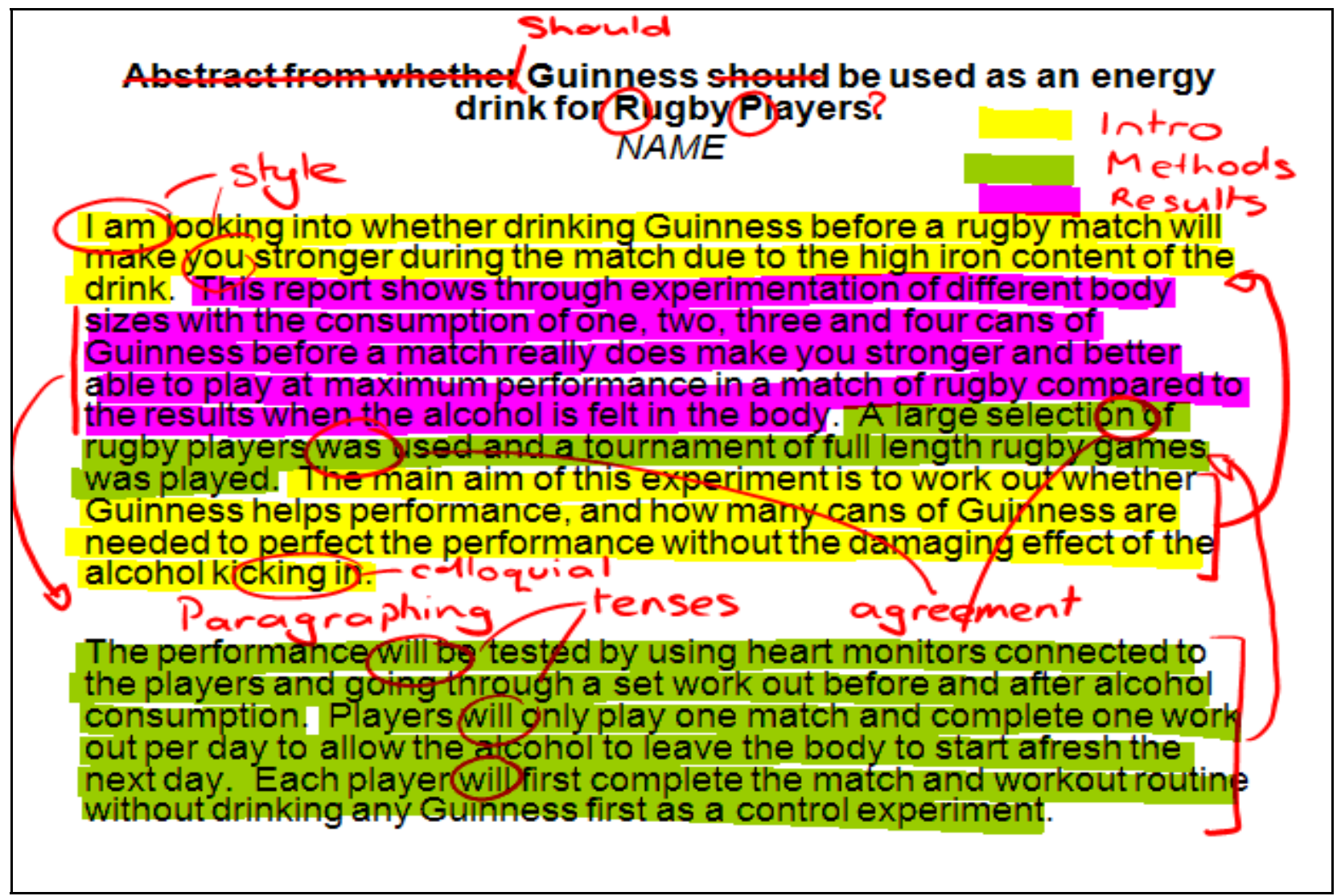

Figure 1 Example of in-class student-led annotation of student writing (a fictitious abstract).

Although submission of these tasks was voluntary, a mean submission rate of approximately $80 \%$ indicates that the students found them valuable. We considered that the active approach to learning was more effective. By equipping the students with the skills to analyse structure there would be greater likelihood of transferring this learning to their own writing.

\section{Conversations}

\section{Between learning developer and subject specialist}

Conversations between the LD and SS are key to the scaffolding process underpinning the transition from study skills to the embedded teaching of writing. The LD has the stance of a social scientist investigating writing practices in a department. His role was to identify the main text types and compare them with other scientific and technological fields to uncover 
how text types differ. He conducted in-depth analysis of text organisation to determine how it functioned at section level as well as macro level. This required conversations with the SS to explore the discoursal and conceptual framework of the subject.

The SS needed conversations with the LD to bring out her tacit writing knowledge; in our experience SS staff know when writing is incorrect, but not necessarily why, and find it hard to explain to students how to improve their work. Here, the scaffolding process involved identifying values, expectations, text types and areas of priority for the department.

\section{Between staff and students}

Throughout the module, the SS used informal conversations with students to evaluate the course and the materials. Being a science subject, there were frequent opportunities for dialogue with students during practical classes, which were used to find out which delivery methods were most effective and how the students found the style of teaching in general. In addition, students frequently came forward at the end of lectures to elucidate specific points about their work. These questions, together with an active discussion forum on the VLE, in which at least $70 \%$ of the students participated, were used to gauge students' understanding and difficulties.

\section{Conclusions}

We have gained a number of insights from this partnership, which may be of use to others embarking on this journey:

- The initial stages of curriculum and material design are time-consuming, and sufficient space needs to be set aside for discussion between LD and SS.

- Both LD and SS need to be open to their own limitations, to respect the skills that the other has to offer and be willing to learn.

- The relationship needs to be flexible. Each partnership is unique, and the LD needs to be able to adapt his/her approach according to the previous experience of the SS. However, each partnership provides the LD with additional materials, which can further enhance subsequent work. 
To summarise, embedding the teaching of writing skills into the curriculum is more effective than separate study skills sessions. We have shown that the combined expertise of the LD and SS are essential to successful delivery. The SS needs to understand the frameworks underpinning successful writing and the LD needs to develop a subject voice and to contextualise the material in a way that relates to the students. By working together, utilising our individual skill sets, an effective, embedded writing course was developed and the target of handover was achieved.

\section{Acknowledgements}

Thanks to our colleagues Ali Cooper and Tony Luxon in CELT for their encouragement and valuable discussions.

\section{References}

Cottrell, S. (2001) Teaching Study Skills and Supporting Student Learning. Basingstoke: Palgrave Macmillan.

Dudley-Evans, T. and St John, M. (1998) Developments in English for Specific Purposes: A multi disciplinary approach. Cambridge: CUP.

Lea, M.R. (2004) 'Academic literacies: pedagogy for course design', Studies in Higher Education 29(6) pp 739-756.

Lea, M.R. and Street, B.V. (1998) 'Student writing in higher education: An academic literacies approach', Studies in Higher Education 23(2) pp 157-172.

Lea, M.R. and Street, B.V. (2006) 'The 'Academic Literacies' model: theory and applications', Theory into Practice 45 pp 368-377.

Spiller, D. and Fraser, D. (1999) 'Writing to learn: a collaborative endeavour', Innovations in Education and Teaching International 36(2) pp 137-144. 
Swales, J. (1990) Genre Analysis: English in Academic and Research Settings. Cambridge: CUP.

Weissburg, R. and Buker, S. (1990) Writing Up Research: Report Writing for Students of English. New Jersey: Prentice Hall.

Willis, J. (1996) A Framework for Task-Based Learning. Harlow: Longman.

Winch, C. and Wells, P. (1995) 'The quality of student writing in higher education: a cause for concern?', British Journal of Educational Studies 23(1) pp 75-87.

Wingate, U. (2006) 'Doing away with study skills', Teaching in Higher Education 11(4) pp 457-469.

\section{Author details}

Robert Blake is the Academic Support Tutor for the Faculty of Science and Technology, working in the Student Learning Development Centre, CELT in Lancaster University.

Jacqueline Pates is a lecturer in the Lancaster Environment Centre at Lancaster University with research interests in environmental radioactivity. 